\title{
Prognostic Factors in Septic Shock Patients on Arrival at Emergency Department
}

\author{
Seong Yeob Lee, Jin Joo Kim, Jae Ho Jang ${ }^{1}$, In Cheol Hwang ${ }^{2}$ \\ ${ }^{1}$ Department of Emergency Medicine, Gachon University Gil Medical Center, Incheon, ${ }^{2}$ Department of Family Medicine, Gachon \\ University Gil Medical Center, Incheon, Korea
}

Corresponding Author:

Jin Joo Kim, MD, PhD

Department of Emergency Medicine,

Gachon University Gil Medical Center,

Namdong-daero 774 beon-gil, Namdong-gu,

Incheon 21565, Korea

Tel: $+82-32-460-3015$

Fax: +82-32-460-3019

E-mail: empearl@gilhospital.com

Co-corresponding Author:

In Cheol Hwang, MD, PhD

Department of Family Medicine, Gachon

University Gil Medical Center, Namdong-daero

774 beon-gil, Namdong-gu, Incheon 21565,

Korea

Tel: $+82-32-460-3354$

Fax: +82-32-460-3019

E-mail: spfe0211@gmail.com

Received: September 22, 2017

Revised: October 27, 2017

Accepted: October 27, 2017

\begin{abstract}
Background: In this study, we evaluated the prognostic factors in patients with septic shock who were managed at an Emergency Department (ED). Methods: This retrospective study was conducted through a chart review of the emergency medical records of all patients with septic shock who were over 18 years of age and managed and hospitalized in the ED from January 2008 to September 2014 at 1 regional emergency center in South Korea. The outcome sought was mortality at 30 days after ED arrival. Results: Of the 648 patients admitted to the ED during the study period, 187 patients $(28.9 \%)$ died. Factors associated with 30 -day mortality in a multiple logistic regression analysis were elderly patients ( $>70$ years), acute physiology and chronic health evaluation II, leukopenia (white blood cell count $<4,000 / \mathrm{mm}^{3}$ ), prolonged international normalized ratio above 1.2 , hypoxemia $\left(\mathrm{pO}_{2}<83 \mathrm{mmHg}\right)$, lactate level $(>4.0 \mathrm{mmol} / \mathrm{L})$, pneumonia-related sepsis, and history of tuberculosis, respectively. Conclusion: An age of over 70 years was related to mortality in septic shock; however, other various laboratory results and biomarkers were also related to mortality and some factors even demonstrated a stronger relationship than age. Treatment should not be limited among elderly septic shock patients due to an ED physician's prejudice. Instead, ED physicians should make decisions regarding the care of septic shock patients by considering various factors including unstable clinical signs, laboratory findings, lactate, and source of infection, in addition to the patient's age, in order to produce better outcomes.
\end{abstract}

Key Words: Prognosis, Septic shock, Frail elderly, Biomarkers, Emergency Department

\section{INTRODUCTION}

Sepsis and septic shock are the most common critical diseases in the Emergency Department (ED) and it is important to diagnose and treat septic shock early to improve morbidity and mortality in the ED. The short-term mortality of septic shock patients was estimated to be $20 \%-30 \%$ and it soared to $50 \%$ in patients with sepsis and septic shock ${ }^{11}$. The definitions of sepsis and septic shock were simply modified recently in the third international consensus definitions ${ }^{2}$. The quick sequential organ failure assessment (SOFA), which includes the mental state, blood pressure, and respiratory rate, has been introduced to evaluate patients with sepsis and septic shock and the importance of lactate was emphasized again ${ }^{2,3}$. Because of this high mortality rate, knowing the demographics and risk factors of patients with critical illnesses in the ED would be helpful for generating better patient outcomes.
During the last 20 years, the elderly population increased considerably all over the world, and old age is a risk factor in various critical illnesses including sepsis and septic shock ${ }^{4)}$. In addition to the state of immunosenescence that predisposes the elderly to an increased rate of sepsis, there are also alterations in the body's response to sepsis that can lead to a more severe presentation of the infection ${ }^{5}$. In this case, the immune system is abnormal and the pathophysiology of the immunosenescence is complex and multifactorial ${ }^{6)}$. In this study, the prognostic factors, especially age, in patients with septic shock that were managed at the ED for mortality and morbidity were evaluated retrospectively.

\section{MATERIALS AND METHODS}

\section{Study Population}

This study was retrospectively conducted in patients who 
were diagnosed and treated after being identified as having septic shock in a single ED from January 2008 to September 2014. The study institution is a 1,300-bed university hospital with approximately 90,000 patients visiting the ED annually and an emergency intensive care unit (ICU) census of 900. The inclusion criteria was septic shock defined as a systolic blood pressure below $90 \mathrm{mmHg}$, which was retrospectively confirmed via medical records, measured on arrival at the ED and via imaging studies in adult patients that were over 18 years of age. Patients were excluded if they had no clinical symptoms of infection including fever or generally known clinical signs of each organ's infection (e.g., cough and sputum for pneumonia, urinary difficulties in urinary tract infections), died in the ED, had an obscure cause of death according to the medical records or had insufficient medical records.

\section{Clinical Evaluation and Outcomes}

Basal patients' characteristics were collected including age, sex, underlying disease, blood pressure, respiratory rate, body temperature, and the acute physiology and chronic health evaluation (APACHE) II score. From the medical records, the laboratory findings and imaging studies were also reviewed by 1 resident and supervised by a professor. Emergency routine laboratory results were obtained via venous sampling within 1 hour after arrival to the ED. Partial oxygen, carbon dioxide pressure and lactate level were measured via arterial blood gas analysis after arrival to the ED within several minutes by physicians who received regular routine education about performing the arterial blood gas analysis method and typically had experience performing that procedure for several months to years. The arterial blood gas analysis was measured by a GEM PREMIER 3500 (Instrumentation Laboratory, Bedford, MA, USA) in the ED. The outcome sought was 30-day mortality after visiting the ED.

\section{Statistical Analysis}

Statistical analyses were performed using the STATA/SE 9.0 (StataCorp LP., College Station, TX, USA) and a p-value of less than 0.05 was considered statistically significant. The Student t-test and the chi-square test were used to compare the clinical differences between the 2 groups in outcomes, and single and multiple variable logistic regression model analyses were performed to estimate the odds ratios (ORs) for mortality along with 95\% confidence intervals (Cls). Statistical significance was defined as a p-value of less than 0.05 .

\section{RESULTS}

Fig. 1 shows the flow diagram of this study. A total of 648 patients were ultimately enrolled in the study during the study period, of which, 461 patients (71.1\%) survived. Age, systolic and diastolic blood pressures, heart rate, APACHE II score, hemoglobin, international normalized ratio (INR), creatinine, $\mathrm{pH}, \mathrm{pO}_{2}$, serum lactate, and source of pneumonia infection were compared between the survivor and nonsurvivor groups $(p<0.05)$ (Table 1$)$. The multiple logistic regression analysis demonstrated that elderly patients ( $>70$ years old) (OR, 2.24; 95\% Cl, 1.39-3.63), increased APACHE II score (per 1 point) (OR 1.05, 95\% Cl, 1.03-1.08), leukopenia (white blood cell count $<4,000 / \mathrm{mm}^{3}$ (OR, 2.91; 95\% Cl, 1.34-6.34), prolonged INR (>1.2) (OR, $1.71 ; 95 \% \mathrm{Cl}, 1.06-2.76)$, hypoxemia $\left(\mathrm{pO}_{2}<83 \mathrm{mmHg}\right)(\mathrm{OR}, 1.92 ; 95 \% \mathrm{Cl}, 1.09-3.40)$, serum lactate level (>4.0 mmol/L) (OR, 2.16; 95\% Cl, 1.31-3.56), pneumonic septic shock (OR, 2.73;95\% Cl, 1.58-4.71), and history of tuberculosis (OR, 3.04; 95\% Cl, 1.37-6.75), respectively, were associated with 30-day mortality (Table 2). Among the survivors of septic shock 30 days after arrival at the $E D$, there was a statistically significant difference between the ICU care duration and serum lactate levels (Fig. 2).

\section{DISCUSSION}

In this study, various factors including age were related to mortality in septic shock patients that visited the ED during the study period. Nasa et al. ${ }^{7)}$ reported the outcomes among the elderly and very elderly in severe sepsis who were admitted to the ICU. Of the 132 patients with severe sepsis, only the age of the patients independently predicted ICU mortality. Kaukonen et al. ${ }^{8)}$ reported a decrease in mortality from $35.0 \%$ to $18.4 \%$ among a sample of 101,604 patients with severe sepsis from 171 ICUs in Australia and New Zealand from 2000 to 2012. Regardless of whether age factors were with or without comorbidities, mortality increased as age increased in both 2000 and 2012. Usually, the outcomes of geriatric patients after critical illness are considered worse than younger patients ${ }^{9}$; consequently, physicians occasionally relinquish resuscitation attempts after minimal effort and patients receive early do-not-resuscitate orders after admission to the $\mathrm{ICU}^{10)}$. The combined effect of aging and sepsis on the coagu-

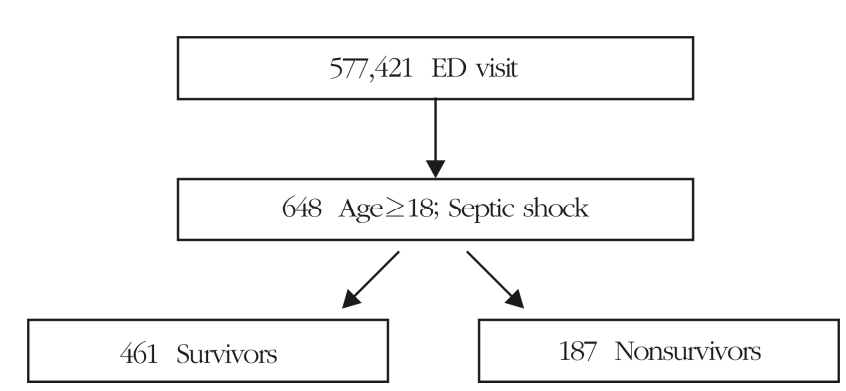

Fig. 1. This is a flow diagram of this study. ED, Emergency Department. 
Seong Yeob Lee, et al.

lation cascade partially explains the higher short survival rates with drotrecogin $\alpha$ (activated) in the Protein C Worldwide Evaluation of Severe Sepsis (PROWESS) trial ${ }^{11)}$. There may be no wonder that age was related to mortality; however, the point is that age was not the sole factor related to mortality in septic shock patients. The management of septic

Table 1. Characteristics, by 30 -day mortality $(n=648)$

\begin{tabular}{|c|c|c|c|c|}
\hline Characteristic & Total $(n=648)$ & Survivors $(n=461)$ & Nonsurvivors $(n=187)$ & $\mathrm{p}$-value \\
\hline Age (yr) & $68.4 \pm 14.2$ & $66.6 \pm 14.4$ & $73.0 \pm 12.7$ & $<0.001$ \\
\hline Female sex $(\%)$ & 44.9 & 46.2 & 41.7 & 0.298 \\
\hline \multicolumn{5}{|l|}{ Vital signs } \\
\hline Systolic blood pressure (mmHg) & $78.5 \pm 15.6$ & $80.2 \pm 13.5$ & $740.3 \pm 190.1$ & $<0.001$ \\
\hline Diastolic blood pressure (mmHg) & $47.5 \pm 13.5$ & $48.8 \pm 12.4$ & $440.1 \pm 150.4$ & $<0.001$ \\
\hline Heart rate $(/ \mathrm{min})$ & $100.5 \pm 26.2$ & $98.8 \pm 25.3$ & $1,040.7 \pm 280.0$ & 0.009 \\
\hline Respiratory rate (/min) & $22.3 \pm 5.5$ & $22.3 \pm 5.1$ & $220.4 \pm 60.3$ & 0.781 \\
\hline Body temperature $\left({ }^{\circ} \mathrm{C}\right)$ & $36.9 \pm 3.4$ & $37.0 \pm 2.7$ & $360.5 \pm 40.7$ & 0.055 \\
\hline CVP & $11.8 \pm 6.9$ & $11.9 \pm 6.7$ & $11.5 \pm 7.5$ & 0.550 \\
\hline APACHE II & $23.0 \pm 10.0$ & $21.0 \pm 9.5$ & $27.0 \pm 9.8$ & $<0.001$ \\
\hline \multicolumn{5}{|l|}{ Laboratory results } \\
\hline Hemoglobin (g/dL) & $11.2 \pm 2.4$ & $11.3 \pm 2.3$ & $100.7 \pm 20.5$ & 0.005 \\
\hline White blood cell count $\left(/ \mathrm{mm}^{3}\right)$ & $14.4 \pm 9.4$ & $14.7 \pm 8.1$ & $130.5 \pm 120.1$ & 0.148 \\
\hline Platelet $\left(10^{3} / \mathrm{mL}\right)$ & $204.3 \pm 115.5$ & $206.6 \pm 109.5$ & $1,980.8 \pm 1,290.4$ & 0.442 \\
\hline INR & $1.33 \pm 0.55$ & $1.30 \pm 0.51$ & $10.40 \pm 00.63$ & 0.028 \\
\hline $\mathrm{CRP}(\mathrm{mg} / \mathrm{dL})$ & $14.5 \pm 9.5$ & $14.4 \pm 9.6$ & $140.7 \pm 90.2$ & 0.718 \\
\hline Creatinine $(\mathrm{mg} / \mathrm{dL})$ & $1.62 \pm 1.17$ & $1.57 \pm 1.13$ & $10.77 \pm 10.24$ & 0.049 \\
\hline AST (IU/L) & $83.8 \pm 297.5$ & $75.4 \pm 303.7$ & $1,040.6 \pm 2,810.5$ & 0.258 \\
\hline ALT (IU/L) & $48.0 \pm 155.0$ & $47.0 \pm 173.6$ & $500.3 \pm 950.0$ & 0.806 \\
\hline $\mathrm{pH}$ & $7.38 \pm 0.13$ & $7.40 \pm 0.11$ & $70.36 \pm 00.14$ & $<0.001$ \\
\hline $\mathrm{pCO}_{2}(\mathrm{mmHg})$ & $34.3 \pm 14.1$ & $33.7 \pm 13.3$ & $350.7 \pm 150.8$ & 0.105 \\
\hline $\mathrm{pO}_{2}(\mathrm{mmHg})$ & $73.6 \pm 37.0$ & $76.7 \pm 36.5$ & $660.5 \pm 370.2$ & 0.002 \\
\hline $\mathrm{HCO}_{3}(\mathrm{mEq} / \mathrm{L})$ & $20.5 \pm 6.7$ & $20.7 \pm 6.1$ & $200.0 \pm 70.8$ & 0.267 \\
\hline Lacatate $(\mathrm{mmol} / \mathrm{L})$ & $3.2 \pm 2.9$ & $2.7 \pm 2.5$ & $40.4 \pm 30.3$ & $<0.001$ \\
\hline Positive culture (\%) & 27.0 & 24.8 & 32.3 & 0.054 \\
\hline \multicolumn{5}{|l|}{ Sepsis source (\%) } \\
\hline Pneumonia & 61.2 & 54.6 & 770.5 & $<0.001$ \\
\hline Urinary tract infection & 29.8 & 35.4 & 160.0 & \\
\hline Biliary tract infection & 1.7 & 1.5 & 20.1 & \\
\hline Gastroenteritis & 1.6 & 2.0 & 00.5 & \\
\hline Others & 5.7 & 6.5 & 30.7 & \\
\hline \multicolumn{5}{|l|}{ Comorbid disease (\%) } \\
\hline Stroke & 0.9 & 0.4 & 20.1 & 0.040 \\
\hline Hypertension & 38.4 & 38.2 & 390.0 & 0.838 \\
\hline $\mathrm{DM}$ & 26.9 & 26.7 & 270.3 & 0.878 \\
\hline Asthma & 3.4 & 3.5 & 30.2 & 0.867 \\
\hline COPD & 6.6 & 6.3 & 70.5 & 0.579 \\
\hline Tuberculosis & 9.6 & 7.6 & 140.4 & 0.007 \\
\hline AIDS & 0.6 & 0.2 & 10.6 & 0.041 \\
\hline Time from ED visit to start antibiotics (hr) & $5.4 \pm 3.2$ & $5.4 \pm 3.0$ & $5.2 \pm 3.6$ & 0.494 \\
\hline
\end{tabular}

Values are presented as mean \pm standard deviation unless otherwise indicated.

CVP, central venous pressure; APACHE, acute physiology and chronic health evaluation; INR, international normalized ratio; CRP, C-reactive protein; AST, aspartate transaminase; ALT, alanine transaminase; DM, diabetes mellitus; COPD, chronic obstructive pulmonary disease; AIDS, acquired immune deficiency syndrome; ED, Emergency Department. 
Table 2. Factors related to 30 -day mortality $(n=648)$

\begin{tabular}{|c|c|c|c|c|}
\hline \multirow{2}{*}{ Variable } & \multicolumn{2}{|c|}{ Univariate } & \multicolumn{2}{|c|}{ Stepwise multivariate } \\
\hline & OR $(95 \% \mathrm{CI})$ & $\mathrm{p}$-value & Adjusted OR $(95 \% \mathrm{CI})$ & p-value \\
\hline Elderly (>70 yr) & $2.31(1.62-3.29)$ & $<0.001$ & $2.24(1.39-3.63)$ & 0.001 \\
\hline \multicolumn{5}{|l|}{ Vital signs } \\
\hline $\mathrm{SBP}<90 \mathrm{mmHg}$ & $1.53(1.07-2.17)$ & 0.019 & - & - \\
\hline $\mathrm{DBP}<60 \mathrm{mmHg}$ & $1.48(1.01-2.17)$ & 0.045 & - & - \\
\hline Heart rate $>100 / \mathrm{min}$ & $1.72(1.22-2.42)$ & 0.002 & - & - \\
\hline Increased APACHE II (per 1 point) & $1.06(1.04-1.09)$ & $<0.001$ & $1.05(1.03-1.08)$ & $<0.001$ \\
\hline \multicolumn{5}{|l|}{ Laboratory finding } \\
\hline Hemoglobin $<10 \mathrm{~g} / \mathrm{dL}$ & $1.44(1.00-2.06)$ & 0.047 & - & - \\
\hline 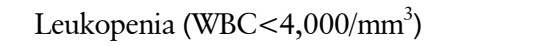 & $3.37(1.86-6.08)$ & $<0.001$ & $2.91(1.34-6.34)$ & 0.007 \\
\hline Thrombocytopenia (platelet $<150\left[10^{3} / \mathrm{mL}\right]$ ) & $1.44(1.00-2.05)$ & 0.044 & - & - \\
\hline Prolonged INR (>1.2) & $1.61(1.14-2.28)$ & 0.007 & $1.71(1.06-2.76)$ & 0.029 \\
\hline AST>40 IU/L & $1.45(1.02-2.05)$ & 0.037 & - & - \\
\hline Acidosis $(\mathrm{pH}<7.35)$ & $2.79(1.95-4.00)$ & $<0.001$ & - & - \\
\hline Hypoxemia $\left(\mathrm{pO}_{2}<83 \mathrm{mmHg}\right)$ & $2.06(1.38-3.07)$ & $<0.001$ & $1.92(1.09-3.40)$ & 0.025 \\
\hline Acidosis $\left(\mathrm{HCO}_{3}<18 \mathrm{mEq} / \mathrm{L}\right)$ & $1.58(1.11-2.26)$ & 0.012 & - & - \\
\hline Lactate $(>4.0 \mathrm{mmol} / \mathrm{L})$ & $2.61(1.81-3.75)$ & $<0.001$ & $2.16(1.31-3.56)$ & 0.003 \\
\hline \multicolumn{5}{|l|}{ Source of infection } \\
\hline Pneumonia & $2.89(1.96-4.26)$ & $<0.001$ & $2.73(1.58-4.71)$ & $<0.001$ \\
\hline UTI & $0.35(0.23-0.54)$ & $<0.001$ & - & - \\
\hline Tuberculosis history & $2.05(1.20-3.50)$ & 0.008 & $3.04(1.37-6.75)$ & 0.006 \\
\hline
\end{tabular}

OR, odds ratio; CI, confidence interval; SBP, systolic blood pressure; DBP, diastolic blood pressure; INR, international normalized ratio; AST, aspartate transaminase; UTI, urinary tract infection.

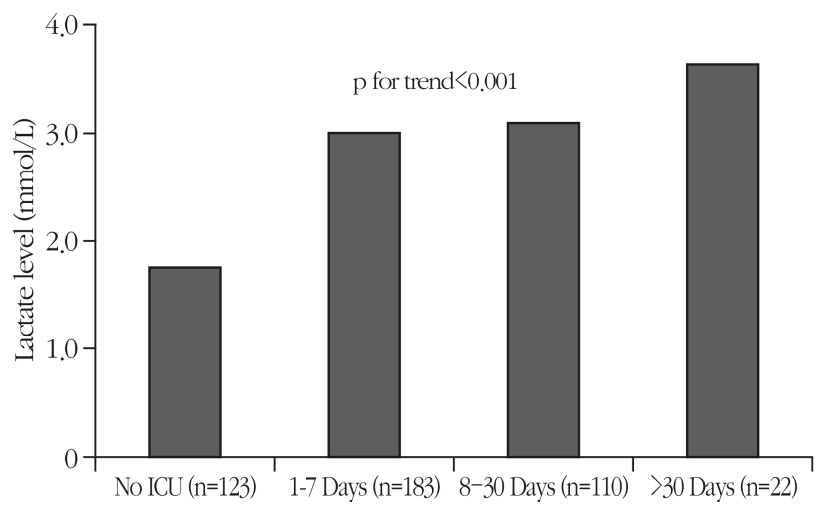

Fig. 2. Relationship between intensive care unit (ICU) care duration and lactate levels at Emergency Department among 30-day survivors from sepsis.

shock in elderly patients should be performed per the International Surviving Sepsis Guidelines in the same manner aswould be applied with young patients ${ }^{2)}$. Muessig et al. ${ }^{12)}$ demonstrated that octogenarians admitted to a medical ICU exhibited higher mortality than younger patients, but still had considerable life expectancy after ICU admission. Furthermore, they identified other stronger risk factors for long-term survival than age. Some physicians suggested that physiology rather than age should be applied to medical decisions and care $^{13,14)}$. While age is an important factor in critical illness mortality, other physiological factors are associated with aging such as underlying diseases and comorbidity. The poor prognostic factors in elderly patients with severe sepsis include the presence of shock, elevated serum lactate levels, and organ failure, especially respiratory and cardiac failure ${ }^{15}$. Kim et al. ${ }^{16)}$ reported that in one geriatric hospital, the transfer to an acute care setting reduced mortality when patients with pneumonia had factors' comorbidities greater than 4.

Comorbidities are also important factors; in this study, a history of respiratory tuberculosis was related to mortality. That result was not explained clearly by references; pneumonia was the greatest source of infection in our patients' data at over $60 \%$. Further studies are needed to better understand the relationship between comorbidities and mortality in septic shock following the source of the infection.

The leukocyte count that is included in the APACHE II score estimates ICU mortality; both lueukocytosis and leukopenia increase mortality. In many stratification models, the sepsis score includes leukocyte counts ${ }^{17,18)}$. In this study, leukopenia below $4,000 / \mathrm{m}^{3}$ was an independent factor related to 30-day mortality. Coagulopathy can be life-threatening. Platelet counts, activated partial thromboplastin time, INR, antithrombin, fibrinogen, and D-dimer reflect coagulopathy in critical illness. The platelet dysfunction in critical illness 
is of a multifactorial origin that is platelet membrane damage, release of platelet granule contents, fibrin degradation products, and others ${ }^{19,20)}$. The platelet count that is included in the SOFA score predicts ICU mortality based on laboratory results and clinical data. In this study, a prolonged INR of over 1.2 was an independent mortality risk factor in septic shock patients in the ED compared to thrombocytopenia.

Recently, new biomarkers were studied for the prediction of mortality in sepsis like procalcitonin, presepsin, galectin-3, matrix metalloproteinases, tissue inhibitors of metalloproteinases, serum oxygen radical activity, and total antioxidant capacity ${ }^{21-24)}$. These biomarkers have been studied in various fields; but they have not yet been established. Many articles have reported that lactate is a good outcome predictor of sepsis and septic shock; however, controversies about lactate in sepsis and septic shock still remain ${ }^{25-28}$. In spite of these controversies, many physicians evaluate lactate in sepsis and septic shock. Lactate could be measured easily via the point of care testing of arterial blood gas analysis within several minutes, immediately after the arrival of critical patients in the ED. In this study, an initial hyperlactatemia on arrival at the $E D$ of over $4.0 \mathrm{mmo} / \mathrm{L}$ also related to mortality, and furthermore related to ICU stay. Lactate could have been measured in the arterial or venous blood, obtained in the author's ED, and easily measured via arterial blood gas analysis at bedside within several minutes after arrival at the ED. Due to this easy accessibility and as a good predictor of outcomes, isolated serum lactate levels should be used in the ED to alert physicians about the patient's condition and to enable treatment more aggressively at the early stage. ED physicians should make decisions comprehensively with reference to the clinical condition and the biomarkers for the treatment management of elderly septic shock patients.

This study had some limitations. First, it was a retrospective study that was conducted at a single center. Second, laboratory results could have varied according to the condition of each patient. Third, arterial blood gas analysis was performed by different physicians in the ED.

In conclusion, an age of over 70 years was related to mortality in septic shock. However, other various laboratory results and biomarkers were also related to mortality and some factors even had a stronger relationship than age. Treatment management should not be limited in elderly septic shock patients due to an ED physician's prejudice. ED physicians should make decisions regarding the care of septic shock patients by considering various factors including unstable clinical signs, laboratory findings, lactate, and the source of infection, in addition to age, to produce better outcomes.

Conflicts of Interest Disclosures: The researchers claim no conflicts of interest.

\section{REFERENCES}

1. Wang HE, Shapiro NI, Angus DC, Yealy DM. National estimates of severe sepsis in United States emergency departments. Crit Care Med 2007;35:1928-36.

2. Singer M, Deutschman CS, Seymour CW, Shankar-Hari M, Annane D, Bauer M, et al. The Third International Consensus Definitions for Sepsis and Septic Shock (Sepsis-3). JAMA 2016;315: 801-10.

3. Seymour CW, Liu VX, Iwashyna TJ, Brunkhorst FM, Rea TD, Scherag A, et al. Assessment of clinical criteria for sepsis: for the third international consensus definitions for sepsis and septic shock (Sepsis-3). JAMA 2016;315:762-74.

4. United Nations Population Division, Department of Economic and Social Affairs. World population prospects the 2010 revision [Internet]. New York: United Nations; 2010 [cited 2017 Apr 1]. Available at: http://www.un.org/en/development/desa/publications/ world-population-prospects-the-2010-revision.html.

5. Nasa P, Juneja D, Singh O. Severe sepsis and septic shock in the elderly: an overview. World J Crit Care Med 2012;1:23-30.

6. Opal SM, Girard TD, Ely EW. The immunopathogenesis of sepsis in elderly patients. Clin Infect Dis 2005;41 Suppl 7:S504-12.

7. Nasa P, Juneja D, Singh O, Dang R, Arora V. Severe sepsis and its impact on outcome in elderly and very elderly patients admitted in intensive care unit. J Intensive Care Med 2012;27:179-83.

8. Kaukonen KM, Bailey M, Suzuki S, Pilcher D, Bellomo R. Mortality related to severe sepsis and septic shock among critically ill patients in Australia and New Zealand, 2000-2012. JAMA 2014;311:1308-16.

9. Ridley S, Jackson R, Findlay J, Wallace P. Long term survival after intensive care. BMJ 1990;301:1127-30.

10. Hemphill JC 3rd. Do-not-resuscitate orders, unintended consequences, and the ripple effect. Crit Care 2007;11:121.

11. Ely EW, Angus DC, Williams MD, Bates B, Qualy R, Bernard GR. Drotrecogin alfa (activated) treatment of older patients with severe sepsis. Clin Infect Dis 2003;37:187-95.

12. Muessig JM, Masyuk M, Nia AM, Franz M, Kabisch B, Kelm $\mathrm{M}$, et al. Are we ever too old?: characteristics and outcome of octogenarians admitted to a medical intensive care unit. Medicine (Baltimore) 2017;96:e7776.

13. Alexander KP, Anstrom KJ, Muhlbaier LH, Grosswald RD, Smith PK, Jones RH, et al. Outcomes of cardiac surgery in patients $>$ or $=80$ years: results from the National Cardiovascular Network. J Am Coll Cardiol 2000;35:731-8.

14. Marik PE. Management of the critically ill geriatric patient. Crit Care Med 2006;34(9 Suppl):S176-82.

15. Vosylius S, Sipylaite J, Ivaskevicius J. Determinants of outcome in elderly patients admitted to the intensive care unit. Age Ageing 200534:157-62.

16. Kim CH, Kwak ST, Song IC. Pneumonia observed in a geriatric hospital. J Korean Geriatr Soc 2015;19:80-8.

17. Shapiro NI, Trzeciak S, Hollander JE, Birkhahn R, Otero R, Osborn TM, et al. A prospective, multicenter derivation of a biomarker panel to assess risk of organ dysfunction, shock, and death in emergency department patients with suspected sepsis. Crit Care Med 2009;37:96-104. 
18. Wong HR, Lindsell CJ, Pettilä V, Meyer NJ, Thair SA, Karlsson $\mathrm{S}$, et al. A multibiomarker-based outcome risk stratification model for adult septic shock*. Crit Care Med 2014;42:781-9.

19. Boldt J, Menges T, Wollbrück M, Sonneborn S, Hempelmann G. Platelet function in critically ill patients. Chest 1994;106: 899-903.

20. Bick RL. Platelet function defects: a clinical review. Semin Thromb Hemost 1992;18:167-85.

21. Kim H, Hur M, Moon HW, Yun YM, Di Somma S; GREAT Network. Multi-marker approach using procalcitonin, presepsin, galectin-3, and soluble suppression of tumorigenicity 2 for the prediction of mortality in sepsis. Ann Intensive Care 2017; $7: 27$.

22. Hayashida K, Kondo Y, Hara Y, Aihara M, Yamakawa K. Headto-head comparison of procalcitonin and presepsin for the diagnosis of sepsis in critically ill adult patients: a protocol for a systematic review and meta-analysis. BMJ Open 2017;7:e014305.

23. Niño ME, Serrano SE, Niño DC, McCosham DM, Cardenas ME, Villareal VP, et al. TIMP1 and MMP9 are predictors of mortality in septic patients in the emergency department and intensive care unit unlike MMP9/TIMP1 ratio: multivariate model. PLoS One 2017;12:e0171191.

24. Jang JY, Lee SH, Shim H, Lee JG. Serum oxygen radical activity and total antioxidation capacity are related with severities of surgical patient with sepsis: prospective pilot study. J Crit Care 2017;39:131-6.

25. Howell MD, Donnino M, Clardy P, Talmor D, Shapiro NI. Occult hypoperfusion and mortality in patients with suspected infection. Intensive Care Med 2007;33:1892-9.

26. Fuller BM, Dellinger RP. Lactate as a hemodynamic marker in the critically ill. Curr Opin Crit Care 2012;18:267-72.

27. Levy MM, Dellinger RP, Townsend SR, Linde-Zwirble WT, Marshall JC, Bion J, et al. The Surviving Sepsis Campaign: results of an international guideline-based performance improvement program targeting severe sepsis. Intensive Care Med 2010;36:222-31.

28. Garcia-Alvarez M, Marik P, Bellomo R. Stress hyperlactataemia: present understanding and controversy. Lancet Diabetes Endocrinol 2014;2:339-47. 